\title{
The Illusion of Magic Realism as a Stratagem in the Hound of the Baskervilles
}

\author{
Moslem Ahmadi*, Mosleh Ahmadi \\ Faculty of Persian and Foreign Languages, Tabriz University, Po box 29 Bahman Boulevard, Tabriz 51666-14766, Iran
}

Corresponding Author: Moslem Ahmadi, E-mail: moslemahmadiapril1992@gmail.com

\section{ARTICLE INFO}

Article history

Received: February 20, 2018

Accepted: April 25, 2018

Published: June 30, 2018

Volume: 9 Issue: 3

Advance access: May 2018

Conflicts of interest: None

Funding: None

\section{Key words:}

Detective Fiction,

Hidden Aspect,

Magic Realism,

Genre, Characters

\begin{abstract}
The focus of the current research is on the relationship between detective fiction and the art of magic. Such a study is important in order to bring into surface a hidden aspect in one of the most popular novels of detective fiction, i.e., The Hound of the Baskervilles and to reconsider this novel from a new and different point of view. The research approach adopted in this paper includes reconsidering the antagonist of the novel as a professional illusionist rather than a mere villain. The findings from this research provide evidence that adopting an illusionist's position can provide the antagonist of the novel with concealment and more freedom of action. The main conclusion drawn from this study is that resort to the art of magic on the antagonist's part can become a great challenge to a detective in a detective novel. This paper recommends that all the antagonists of detective fiction assume hidden roles for achieving their goals not yet known by the readers.
\end{abstract}

\section{INTRODUCTION}

Some of Sir Arthur Conan Doyle's Sherlock Holmes stories seem to be suffused with the illusion of magic realism. The most outstanding paradigm of these stories is Doyle's The Hound of the Baskervilles (1902). At the beginning of the novel, a country physician called Dr James Mortimer tells the renowned sleuthhound Sherlock Holmes, "I came to you, Mr. Holmes, because I recognized that I am myself an unpractical man, and because I am suddenly confronted with a most serious and extraordinary problem" (Doyle, The Hound of the Baskervilles 10). Accordingly, two points make The Hound of the Baskervilles (1902) a suitable case for this study. First, The Hound of the Baskervilles (1902), as a detective novel, invites all to reason and logic. Second, Dr James Mortimer's remark about an extraordinary case introduces a fantastic element into the plot of the novel. In accordance with what was mentioned, the present study aims to find out whether the events narrated in the aforementioned novel give the illusion of magic realism to the readers or to the characters of the novel. To facilitate the process of achieving this aim, the overall research aim is divided into two main goals. On one hand, this study intends to find out what creates in this novel the illusion of magic realism. On the other hand, this study intends to find out what shatters the illusion of magic realism in this novel.

\section{DISCUSSION}

Prior to addressing the main topic of this article, a preliminary explication of magic realism seems indispensable for a thoroughgoing comprehension of the present discussion. As is the case with any other literary movement, magic realism has its own origins. Originally, magic realism was a term for describing a school of surrealist German painters in the 1920 s before entering the realm of modern fiction ("novel"). The roots of magic realism in modern fiction can be traced back to the mid-twentieth century Spanish American writers, especially the appearance of two significant novels in the 1940s: The Guatemalan writer Miguel Angel Asturias' Men of Maize and the Cuban writer Alejo Carpentier's The Kingdom of This World (Milne 437). Like any other literary school, magic realism cannot lend itself to a single and all-inclusive definition due to its broad scope and the variety of works included in it (Reeds 175). For example, some original and young writers of fiction in Britain such as Emma Tennant, Angela Carter, and Salman Rushdie adopted this term in the 1970s and 1980s ("magic realism"). A glance at these British writers' magic realist works reveals many differences between them and their Latin American predecessors. In spite of this, magic realism is usually delineated as a technique depicting magical or unreal elements as a normal component in a realistic or everyday setting (Aljohani 74). One axiom can be derived from this definition: It is the au- 
thor as an authority figure who introduces the supernatural element into the realistic world of the literary work. Unlike the other works of magic realism, the supernatural element is introduced into the realistic world of The Hound of the Baskervilles (1902) by one of the characters, not by the author of the work. This is what causes this type of magic realism to have different targets and purposes. It is also the reason for its failure.

Technique is usually defined as "a method of accomplishing a desired aim" ("technique," def. 2b). Undoubtedly, technique is reckoned as a sine qua non for success in every activity. Magic tricks and illusions are not exempt from this rule. In performing magic tricks and illusions, two elements form technique (Nelms 10). The method of deception is reckoned as the first element (Nelms 10). In the second chapter of the novel, Dr James Mortimer reads Sherlock Holmes and Dr Watson a manuscript about the demise of Sir Hugo Baskerville and a country wench by a great black hound-like beast back in 1742 (Doyle, The Hound of the Baskervilles 16). Dr James Mortimer relates how he beheld a creature like a big black calf on one of his journeys to Baskerville Hall three weeks ere Sir Charles Baskerville's demise (Doyle, The Hound of the Baskervilles 24). Accordingly, the antagonist of the novel, i.e., Stapleton shows Dr James Mortimer an oversized hound in order to make him believe the existence of the legendary hound. As a result, Stapleton succeeds in performing the prerequisite for any successful illusion, i.e., showmanship by means of deception as every professional illusionist does. Technique also includes the illusionist's way of presentation, i.e., the manner of his motion, the manner of his speech, the subject of his speech, his timing, and his deftness in hiding props being used (Nelms 11). Dr James Mortimer tells Sherlock Holmes and Dr Watson how Stapleton was aware of Charles Baskerville's plan of a trip to London due to his state of health and how death came upon Charles Baskerville just ere leaving for London (Doyle, The Hound of the Baskervilles 25). Dr James Mortimer recounts how he found the footsteps of a gargantuan hound by the recently deceased Charles Baskerville's body (Doyle, The Hound of the Baskervilles 26). With the information Stapleton has in mind about Charles Baskerville's plan of a trip to London due to his bad health, he succeeds in murdering Charles Baskerville by performing his illusion, i.e., his magic realism: the existence of a supernatural creature such as a beast-like hound in the real world. Therefore, Stapleton has been successful in utilizing the second element of technique, i.e., meeting the above-mentioned conditions necessary for performing a successful illusion.

Having removed his first target, Stapleton prepares for performing his illusion for the second time. Sir Henry Baskerville, the next heir of the Baskerville Hall gives Sherlock Holmes a note which says, "As you value your life or your reason keep away from the moor" (Doyle, The Hound of the Baskervilles 42-3). Furthermore, Sherlock Holmes finds out that the note has been written by an educated person who wanted to seem uneducated (Doyle, The Hound of the Baskervilles 46). Thus, this note from Stapleton's sister helps Stapleton begin showmanship for his illusion by means of the first element of technique in magic, i.e., decep- tion. Sir Henry also informs Sherlock Holmes that one of his newly-bought boots have been stolen (Doyle, The Hound of the Baskervilles 49). Subsequent to Sherlock Holmes' arrival at the hotel in which Sir Henry Baskerville sojourns, Sir Henry Baskerville apprises Detective Holmes that one of his old black boots has been stolen this time (Doyle, The Hound of the Baskervilles 61). After luncheon, Sir Henry Baskerville finds his missing brown boot under a cabinet (Doyle, The Hound of the Baskervilles 68). Hence Stapleton collects the necessary props for performing his illusion once more.

Meanwhile in the village, Dr Watson is befriended by Rodger Baskerville who conceals his real identity by introducing himself as Stapleton of Merripit House (Doyle, The Hound of the Baskervilles 93). He also introduces Dr Watson his wife as his sister (Doyle, The Hound of the Baskervilles 96). Since misdirection resides in misguiding the audience's senses in order to guard vital details against detection (Maskelyne 117), here our villain resorts to misdirection so that he can lead the village folks' minds away from his Baskerville lineage towards the verisimilitude of his illusion.

The sight of a boy through Mr. Frankland's telescope impels Dr Watson to go to the prehistoric huts on the moor where he encounters Sherlock Holmes to his astonishment (Doyle, The Hound of the Baskervilles 181). After Dr Watson's discovery of Sherlock Holmes' hideout, the latter apprises the former of a close relationship between Stapleton and Mrs. Laura Lyons as well as of the fact that Miss Stapleton is actually Stapleton's spouse (Doyle, The Hound of the Baskervilles 186). Thus, Dr Watson is the first person who finds out about Sherlock Holmes' subterranean plan to disclose Stapleton's illusion of magic realism by hiding in the backstage part of Stapleton's live show. Subsequent to Stapleton's arrival, Sherlock Holmes tells Stapleton that he will be on his way back to London tomorrow (Doyle, The Hound of the Baskervilles 197). By uttering these words, Sherlock Holmes intends to resume his backstage plot to expose Stapleton's great illusion. Having spent a night at the Baskerville Hall, Sherlock Holmes informs Sir Henry Baskerville that he and his assistant, Dr Watson will be on their way back to London today (Doyle, The Hound of the Baskervilles 208). Here, Sherlock Holmes intends to strengthen his and Watson's backstage position in Stapleton's live illusion. Then Sherlock Holmes instructs Sir Henry Baskerville to inform the Stapletons of their departure (Doyle, The Hound of the Baskervilles 208). Finally, Sherlock Holmes asks Sir Henry Baskerville to let his carriage leave and to let the Stapletons know that he intends to return home afoot (Doyle, The Hound of the Baskervilles 209). Here, Sherlock Holmes attempts to manipulate Stapleton's live illusion. So he does by dint of his backstage position.

At the determined night, Sherlock Holmes, Dr Watson, and Lestrade prepare for an ambuscade two hundred yards from the Merripit House (Doyle, The Hound of the Baskervilles 2019). Therefore, they prepare to implement their backstage scheme to foil Stapleton's great live illusion. From their hiding-place, they watch Stapleton's second target, i.e., Sir Henry Baskerville after his egress from the Merripit House (Doyle, The Hound of the Baskervilles 222). Sherlock Holmes manages to slay 
the Hound of the Baskervilles posterior to its attack on Sir Henry Baskerville (Doyle, The Hound of the Baskervilles 224). With a brief scrutiny of the slain hellhound, Dr Watson finds out that Stapleton used phosphorus to give the beast a diabolical semblance (Doyle, The Hound of the Baskervilles 225). Consequently, their backstage position enables them to unravel Stapleton's illusion of magic realism. After their abortive quest for Stapleton, Sherlock Holmes and Dr Watson infer that he has drowned in the Grimpen Mire (Doyle, The Hound of the Baskervilles 232). In their office in Baker Street, Sherlock Holmes tells Dr Watson that Stapleton was indeed a Baskerville (Doyle, The Hound of the Baskervilles 236). Furthermore, he informs Dr Watson that Stapleton's purpose was to own the Baskerville Hall as the family heirloom of the Baskervilles (Doyle, The Hound of the Baskervilles 237). Based on Sherlock Holmes' words, Stapleton was using the illusion of magic realism as a stratagem to obtain wealth.
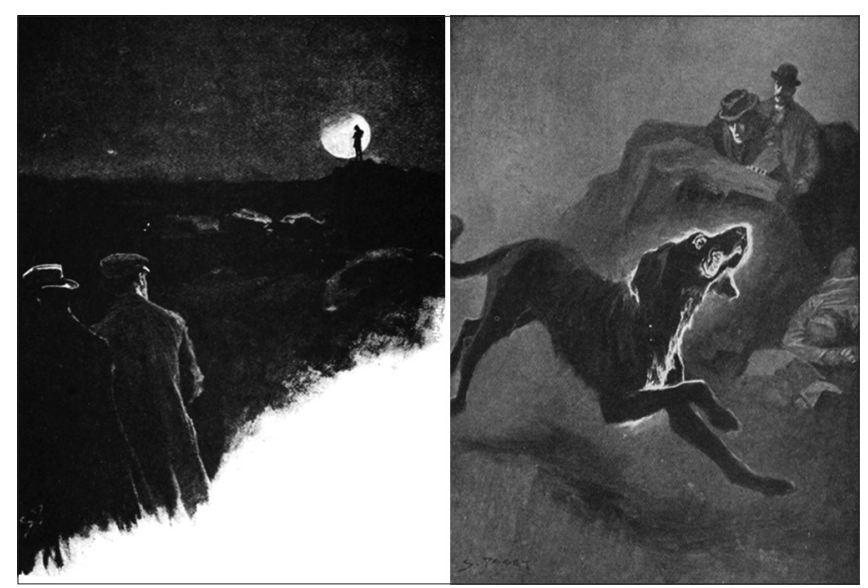

Sherlock Holmes' Silhouette by Sidney Paget

The Hound of the Baskervilles by Sidney Paget

\section{CONCLUSION}

According to the discussions made in the present article, it can be concluded since one of the characters in the novel creates the illusion of magic realism, the events narrated in the aforementioned novel give the illusion of magic realism to the characters of the novel rather than its readers. Had this illusion of magic realism been created by the author, it would have the readers of the novel as its objects. Accordingly, the objects to whom the magic realism is directed depend on the authority figure who creates it. Furthermore, Stapleton's choice of this technique as a stratagem to obtain wealth is what creates in this novel the illusion of magic realism. In this case, Stapleton and the authors of magic realism share a common denominator, i.e., they use magic realism to gain an advantage: whereas the authors use magic realism to cast doubts on the nature of reality and to make the readers concentrate on the act of creation (Milne 437), Stapleton uses it for financial purposes. Finally, it can be said whereas the other characters are the audience and objects of Stapleton's live illusion, it is Sherlock Holmes' presence in the backstage part of Stapleton's live illusion that renders the shattering of this illusion possible.

\section{REFERENCES}

Aljohani, Fayezah M. "Magical Realism and the Problem of Self-Identity as Seen in three Postcolonial Novels." Arab World English Journal 4 (2016): 73-82. Print.

Doyle, A. Conan. The Hound of the Baskervilles. New York City: Grosset \& Dunlap, 1901-1902. Print.

"Magic Realism." The Oxford Companion to English Literature. $6^{\text {th }}$ ed. 2000. Print.

Maskelyne, Nevil, and David Devant. Our Magic: The Art in Magic, the Theory of Magic, the Practice of Magic. $2^{\text {nd }}$ ed. Berkeley Heights: Fleming Book Company, 1946. Print.

Milne, Ira Mark, ed. Literary Movements for Students. $2^{\text {nd }}$ ed. Farmington Hills: Gale Cengage Learning, 2009. Print.

Nelms, Henning. Magic and Showmanship: A Handbook for Conjurers. Mineola: Dover Publications Inc., 2000. Print.

"Novel." A Glossary of Literary Terms. 11 ${ }^{\text {th }}$ ed. 2015. Print.

Reeds, Kenneth. "Magic Realism: A Problem of Definition." Neophilologus 90.2 (2006): 175-196. Print.

“Technique." Def. 2b. Merriam-Webster's Collegiate Dictionary. $11^{\text {th }}$ ed. 2004 . Print. 